\title{
Errata: Initial results of imaging melanoma metastasis in resected human lymph nodes using photoacoustic computed tomography
}

Jithin Jose, ${ }^{a}$ Diederik J. Grootendorst, ${ }^{\text {a }}$ Thomas W. Vijn, ${ }^{\text {a }}$ Michel W. Wouters, ${ }^{b}$ Hester van Boven, ${ }^{c}$ Ton G. van Leeuwen, ${ }^{\text {ad }}$ Wiendelt Steenbergen, ${ }^{a}$ Theo J. M. Ruers, ${ }^{b, e}$ and Srirang Manohar ${ }^{\mathrm{a}}$

a University of Twente, MIRA-Institute for Biomedical Technology and Technical Medicine, Biomedical Photonic

Imaging Group, P.O. Box 217, AE Enschede, 7500 The Netherlands

bNetherlands Cancer Institute-Antoni van Leeuwenhoek Hospital (NKI-AVL), Department of Surgical Oncology, P.O. Box 90203, BE Amsterdam, 1006 The Netherlands

'Netherlands Cancer Institute-Antoni van Leeuwenhoek Hospital (NKI-AVL), Department of Pathology, P.O. Box 90203, BE Amsterdam, 1006 The Netherlands

${ }^{\mathrm{d}}$ University of Amsterdam, Academic Medical Center, Biomedical Engineering and Physics, P.O. Box 22700, DE, Amsterdam, 1100 The Netherlands

eUniversity of Twente, MIRA-Institute for Biomedical Technology and Technical Medicine, P.O. Box 217, AE Enschede, 7500 The Netherlands

[DOI: $10.1117 / 1.3660231]$

This article [J. Biomed. Opt. 16, 096021 (2011)] was originally published online on 23 September 2011 an error in the author list. A middle initial has been added to the author Michel W. Wouters, as it appears above. The article was corrected on 27 October 2011. 